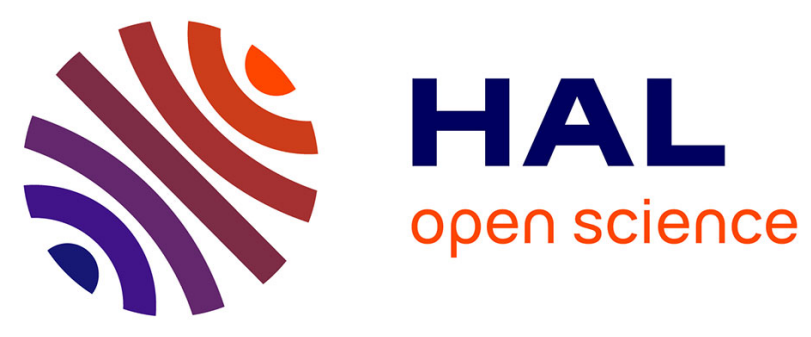

\title{
Bat Overpasses Help Bats to Cross Roads Safely by Increasing Their Flight Height
}

Fabien Claireau, Christian Kerbiriou, Flavien Charton, Cédric de Almeida Braga, Thibaut Ferraille, Jean-François Julien, Nathalie Machon, Benjamin Allegrini, Sébastien Puechmaille, Yves Bas

\section{To cite this version:}

Fabien Claireau, Christian Kerbiriou, Flavien Charton, Cédric de Almeida Braga, Thibaut Ferraille, et al.. Bat Overpasses Help Bats to Cross Roads Safely by Increasing Their Flight Height. Acta Chiropterologica, 2021, 23 (1), pp.189-198. 10.3161/15081109acc2021.23.1.015 . hal-03287052

\section{HAL Id: hal-03287052 https://hal.sorbonne-universite.fr/hal-03287052}

Submitted on 23 Jul 2021

HAL is a multi-disciplinary open access archive for the deposit and dissemination of scientific research documents, whether they are published or not. The documents may come from teaching and research institutions in France or abroad, or from public or private research centers.
L'archive ouverte pluridisciplinaire HAL, est destinée au dépôt et à la diffusion de documents scientifiques de niveau recherche, publiés ou non, émanant des établissements d'enseignement et de recherche français ou étrangers, des laboratoires publics ou privés. 


\title{
Bat overpasses help bats to cross roads safely by increasing their flight height
}

\author{
Fabien Claireau ${ }^{1,2,3,7}$, Christian Kerbiriou ${ }^{1,4}$, Flavien Charton ${ }^{3}$, Cédric De Almeida Braga 3 , \\ Thibaut Ferraille ${ }^{3}$, Jean-François Julien ${ }^{1}$, Nathalie Machon ${ }^{1}$, Benjamin Allegrini ${ }^{3}$, \\ Sebastien J. Puechmaille ${ }^{2,5}$ and Yves Bas ${ }^{1,6}$ \\ ${ }^{1}$ Centre d'Ecologie et des Sciences de la Conservation (CESCO), Muséum National d'Histoire Naturelle, \\ Centre National de la Recherche Scientifique, Sorbonne Université, CP 135, 57 rue Cuvier, 75005 Paris, France \\ ${ }^{2}$ Zoology Institute and Museum, University of Greifswald, Soldmann-Strasse 14, D-17 489 Greifswald, Germany \\ ${ }^{3}$ Naturalia Environnement, Site Agroparc, 20 rue Lawrence Durell, BP 31 285, 84911 Avignon Cedex 9, France \\ ${ }^{4}$ Station de Biologie Marine de Concarneau, Muséum National d'Histoire Naturelle, BP 225, Place de la Croix, \\ 29182 Concarneau cedex, France \\ ${ }^{5} I S E M$, Université Montpellier, CNRS, EPHE, IRD, Montpellier, France \\ ${ }^{6}$ Centre d'Ecologie Fonctionnelle et Evolutive (CEFE), UMR 5175, CNRS - Université de Montpellier - Université Paul-Valéry \\ Montpellier - EPHE, Montpellier, France \\ ${ }^{7}$ Corresponding author: E-mail: f.claireau@naturalia-envrionnement.fr
}

Roads have a multitude of negative effects on wildlife, including bat casualties. Most bat species rely on life history traits characterised by high adult survival (associated with greater longevity) and low reproduction rates (hence slow population growth rates). Therefore, road kills are expected to negatively affect local abundance and bat population dynamics. Bat overpasses are among the proposed improvements intended to increase bat flight height to reduce collisions, but their effectiveness has rarely been tested. In this study, we performed a before-after analysis to assess the effectiveness of one bat overpass on bat flight height. We used a novel approach, the bat tracking toolbox (BTT), to reconstruct bat flight paths from thermal videos. We obtained 268 bat flight paths and our results showed that the flight height of bats increased significantly after the installation of the bat overpass. Considering that bat overpasses can help in some situations to increase habitat connectivity and reduce the collision risk, this mitigation measure needs to be further investigated in different contexts of road construction and/or road requalification.

Key words: bat gantry, before-after analysis, collision, crossing structure, flight paths, mitigation measure, road kills

\section{INTRODUCTION}

Transport networks have been identified as one of the ten main pressures on biodiversity (Maxwell et al., 2016) as their construction contributes to habitat degradation and destruction. Once operational, roads continue to generate negative impacts on wildlife through light, noise, and chemical pollution, direct mortality by collision with vehicles and barrier effects (Forman and Alexander, 1998; Trombulak and Frissell, 2000). These impacts have been identified from individual behaviour all the way up to population densities and dynamics (Bennett, 2017). Indeed, the cumulative ecological effects of the road on biodiversity can extend from 100 to $800 \mathrm{~m}$ (i.e., the road effect-zone) depending the type of road, the traffic volume and the habitat crossed by roads (Forman, 2000; Forman and Deblinger, 2000). For bat, the road-effect zone of major roads can extend up to $5 \mathrm{~km}$ (Claireau et al., 2019c). Depending on the road network densities and/or habitats on both sides of the roads, the cumulative impacts of these disturbances may thus have an impact at the landscape scale (Berthinussen and Altringham, 2012b; van der Ree et al., 2015). Finally, these dramatic changes in landscape configurations have consequences on the overall functionality of ecosystems (Quinn and Harrison, 1988; Saunders et al., 1991; Krauss et al., 2010).

Until recently, despite the large pressure exerted by roads on animals, the effects of roads on insectivorous bats has been poorly documented (Berthinussen and Altringham, 2012b; Kitzes and Merenlender, 2014; Abbott et al., 2015; Claireau et al., 2019c; Medinas et al., 2019, 2021). Indeed, habitat connectivity in the landscape is a key element for 
bats (Hale et al., 2012; Frey-Ehrenbold et al., 2013; Pinaud et al., 2018; Laforge et al., 2019) but the fragmentation effect of road remains poorly evaluated. In addition, even weak road fatalities may contribute to significantly increase the risk of population extinction, especially when breeding colonies are close to a road (Medinas et al., 2013). Indeed, due to their life cycle (i.e., low fecundity, late sexual maturity), their population growth rate heavily depends on adult survival. Hence factors affecting adult survival are of particular interest for conservation. Berthinussen and Altringham (2012a) state that a bat flying less than five meters above a road could be considered to be at collision risk with vehicles. Considering the study of Fensome and Mathews (2016), 85\% of European bats fly up to $5 \mathrm{~m}$ from the ground and so, to be prone at collision risk. Species particularly concerned are Myotis spp., Plecotus spp. and Rhinolophus spp. as they exploit low-altitude ecological niches (Roemer et al., 2019).

In order to reduce road collisions and restore habitat connectivity for bats, a range of mitigation measures have been proposed, including bat overpasses (Møller et al., 2016). Bat overpasses are presumed to function as linear features (e.g., hedgerows) that 'attract' and guide bats across roads and above the traffic, and are thus recommended in the mitigation hierarchy (Berthinussen and Altringham, 2012a; Claireau et al., 2019a, 2019b; Sołowczuk, 2019). While more and more bat overpasses are likely to be constructed across Europe, Møller et al. (2016) stressed the need for a robust evaluation of this mitigation measure to prove its effectiveness. However, peer-reviewed studies investigating bat overpasses are still particularly scarce (Berthinussen and Altringham, 2012a; Claireau et al., 2019a, 2019b; Sołowczuk, 2019) and there is no consensus on their effective. While Berthinussen and Altringham $(2012 a)$ concluded that bat overpasses are ineffective as mitigation measures, Claireau et al. $(2019 a, 2019 c)$ concluded that in some landscape contexts, bat overpasses can contribute to partially restore habitat connectivity. This functional restoration of the connectivity seems to occur when bat overpasses are installed in a narrow commuting route such as a hedgerow. In addition, Sołowczuk (2019) concluded that sustainable crossing conditions depend on general factors (unlit road sections, location on existing commuting routes, features on both sides of the road, lack of road interchanges near the overpass, and attractive hunting grounds nearby) and on main determinants (location in a forest opening, road in a cutting, features on the commuting route, and planting corridors and re-planting of gaps). Due to the scarcity of published studies on this issue and the lack of a larger consensus on the effectiveness of overpasses, conducting a metaanalysis on this issue is not an option at present, and it implies the need for sound research designs involving before-after studies.

The aim of our study was to evaluate whether a bat overpass, as a recommended mitigation measure, contributes to the reduction of road collision risk using a before-after analysis. The study took place at a bat overpass that extended a hedgerow bisected by a highway in an agricultural landscape in Western France. The experiment was conducted from April to September 2016 before the bat overpass was constructed, and from May 2017 to May 2018 after its establishment. Using this experimental design, we tested if this bat overpass contributes to raising bat flight heights.

\section{Materials AND Methods}

\section{Study Site}

The study was carried out in France, which experienced a road increase of 12\% between 1995 and 2015 (MEEM, 2017). We studied one bat overpass located in a rural area (intensive farming) near the city of Niort $\left(46^{\circ} 24^{\prime} \mathrm{W}, 0^{\circ} 35^{\prime} \mathrm{W}\right)$ on the A83 highway (tarmac; four lanes with an emergency lane on each side; speed limit: $130 \mathrm{~km} / \mathrm{h}$; annual average daily traffic: 16,218 vehicles in 2015 - Fig. 1). This highway became operational in 2001 and the bat overpass tested was permanently installed in May 2017. Although in this study, bats were not identified to species level, the known bat species community in this agricultural landscape comprises approximately: Pipistrellus spp. (87\%), Myotis spp. (8\%), Barbastella barbastellus (2\%) (Claireau et al., 2019a, 2019b; more information in Supplementary Appendix S1).

\section{Placement and Features of the Bat Overpass}

The choice of location for the bat overpass followed the conclusions of an independent field study conducted by a consulting firm for 'VINCI-Autoroutes' in order to identify breaking points of the bat commuting route on the A83 highway. This field study was carried out in October 2015 (Naturalia Environnement, 2019). Naturalia Environnement's study identified an important bat commuting route in an agricultural landscape bisected by the A83 highway. This commuting route is a large hedgerow (a disused railway, closed in 1971, and completely reforested, $20 \mathrm{~m}$ wide) that connects two important rivers (Fig. 1).

The bat overpass, installed in May 2017, consists of a traditional gantry for road signs but in this particular case without signs (length: $31.5 \mathrm{~m}$; height: $6 \mathrm{~m}$; beam width: $50 \mathrm{~cm}$ - Fig. 1). Instead of road signs, a diamond mesh metal grate was installed on the gantry with the expectation that it could contribute to 

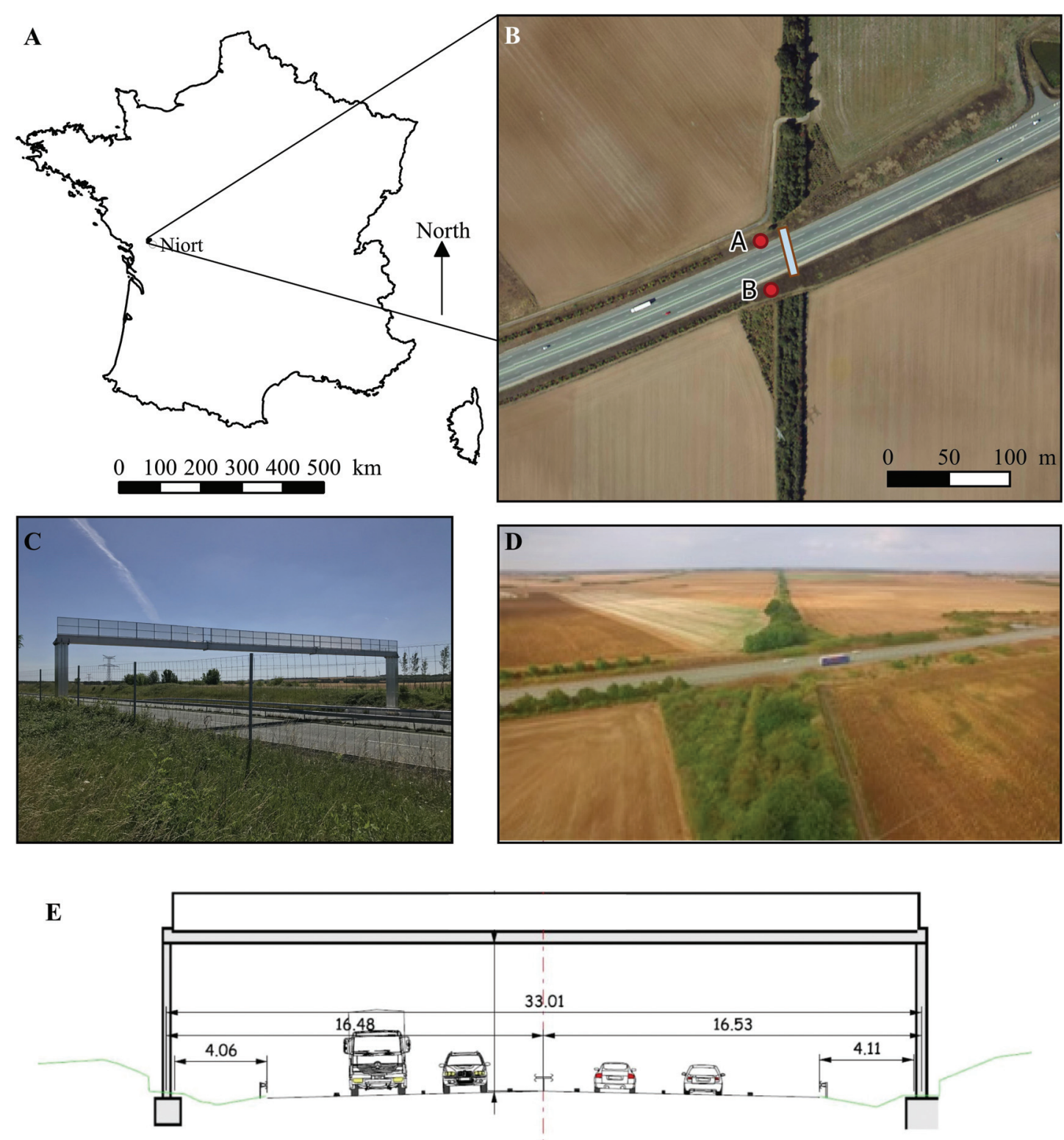

FIG. 1. A — Location of study site; B — Sampling plan: thermal camera (red dot) and bat overpass (solid white line); C - Picture of the gantry; D - Picture of the study site before; E - Technical drawing of the gantry (Source: Institut National de l'Information Géographique et Forestière, Koox-production/VINCI-autoroutes)

reflect bat echolocation signals more efficiently (grate height: $1.5 \mathrm{~m}$; diamond mesh: $4.13 \times 1.3 \mathrm{~cm}$ - Fig. 1$)$. In addition, ten deciduous trees: Acer campestre (height: $4 \mathrm{~m}$; trunk circumference measured at $1 \mathrm{~m}$ : 10 to $12 \mathrm{~cm}$ ) were planted on both sides of the highway in order to guide bats from the hedgerow to the bat overpass.

\section{Sampling Design}

The experiment was carried out before the bat overpass and plantations were set up: monthly from April to September 2016 and replicated after its establishment: monthly from June to September 2017 and in May 2018 (Table 1). This represents 40 observation evenings, 20 before and 20 after the installation of the bat overpass. We performed the visual surveys from two locations, one on either side of the highway (with the same camera). Given that we only used one camera, the two sides of the highway were investigated on different nights. These surveys were realized on both sides of the highway at 30 meters from the rupture of the bat commuting route to study bat flight behaviour over the road on each side of the rupture of the bat commuting route (Fig. 1). The filming was carried out within three hours after the standard sunset time, thus corresponding to the peak activity of bats (Newson et al., 2015). Filming lasted for a total of 44 hours and 21 minutes ( 22 hours and 12 minutes before, 22 hours and 9 minutes after the installation of the bat overpass) equitably distributed before and after the overpass installation, per month and per location (Table 1). 
TABLE 1. Summary of the duration of thermal camera surveys before (2016) and after (2017 and 2018) the installation of the bat overpass

\begin{tabular}{|c|c|c|c|c|c|c|c|c|c|c|}
\hline \multirow{2}{*}{$\begin{array}{c}\text { Survey } \\
\text { point }\end{array}$} & \multicolumn{5}{|c|}{ Before } & \multicolumn{5}{|c|}{ After } \\
\hline & May '16 & June '16 & July '16 & Aug '16 & Sept '16 & June '17 & July '17 & Aug '17 & Sept ' 17 & May '18 \\
\hline A & 1h19 & $2 \mathrm{~h} 22$ & 2h17 & $2 \mathrm{~h} 26$ & $2 \mathrm{~h} 30$ & $2 \mathrm{~h} 21$ & 2h17 & 2h27 & $2 \mathrm{~h} 30$ & 1h19 \\
\hline B & $1 \mathrm{~h} 40$ & $2 \mathrm{~h} 21$ & $2 \mathrm{~h} 22$ & $2 \mathrm{~h} 25$ & $2 \mathrm{~h} 30$ & $2 \mathrm{~h} 21$ & $2 \mathrm{~h} 17$ & $2 \mathrm{~h} 27$ & $2 \mathrm{~h} 30$ & $1 \mathrm{~h} 40$ \\
\hline Total & & & $22 \mathrm{~h} 12$ & & & & & $22 \mathrm{~h} 09$ & & \\
\hline
\end{tabular}

\section{Thermal Video Recording}

In order to characterize bat flight paths, we used a thermal camera: FLIR T640bx (FLIR System, Inc. Wilsonville, OR, USA), equipped with a standard lens with a focal length of 13.1 $\mathrm{mm}$, allowing 16-bit images to be recorded in MPEG4 compression format with a resolution of $640 \times 480$ pixels at a frame rate of approximately 21 frames per second. A manual calibration step to rebalance the temperature levels and ensure that the bats would stand out well on the image was operated by a unique fieldworker before each observation.

\section{Bat Flight Paths Identification}

Human-based detection includes several sources of bias, such as difference between observers (i.e., various level of perception). Moreover, some of these biases vary over time such as concentration or the effect of learning/experience. Thus, to determine bat flight paths and their characteristics, we developed a workflow using a reconstruction of bat flight behaviour, hereafter named Bat Tracking Toolbox (BTT) workflow. This workflow, based on an algorithm, will produce a constant rate of nondetection or false detection. This aspect is of primary interest when the issue is a comparison over time.

The BTT workflow consists of four steps: (i) detection of movements, (ii) matching contour detections, (iii) concatenation of the detected paths, (iv) path classification with assignation of a probability to be a bat or not (Fig. 2) (for more detail see Supplementary Appendix S2). The first step of the BTT is a Python script that detected all moving object present in each frame, such as vehicles, birds, bats... by subtraction of the background and morphological frames. This resulted in the segmentation of the different objects on the frame (Fig. 2 step 1). In a second step, the BTT workflow linked pairs of closest detected objects between consecutive frames to obtain full and partial tracks (Fig. 2 step 2). In a third step, pairs of objects linked in the second step were grouped to form the longest possible sequences of detected objects, potentially flight paths. To avoid partially detected paths (e.g., one true path being detected as multiple 'partial' paths), the previously constituted detected paths were passed into a concatenation algorithm allowing for the absence of detection during a maximum of five consecutive frames (Fig. 2 step 3). In a fourth step, the BTT classified detected paths using Random Forest (Cutler et al., 2007) as a classification algorithm with features of full and partial tracks (Fig. 2 step 4). This part was coded in R (version 3.4.4). In order to distinguish bat flight paths from other detected paths (e.g., insects, birds), we constituted a reference dataset. This training dataset was composed of 196 short videos (average duration of 20 seconds). These videos were chosen to represent situations found in the field with various types of detections to test the robustness of the tool developed: 178 bat flight paths, eight bird flight paths, six insect flight paths and four small mammals appear in a dynamic context consisting of moving vegetation together with road traffic. These videos were all annotated manually by an experienced observer. Finally, using a Random Forest classification, all flight paths have a score between 0 and 1 ( 0 for non-bat and 1 for bat).

\section{Minimising False Negatives Rate}

We used the BTT for all videos filmed on the A83 highway and obtained an average of 500,000 detected paths. Each of them had a confidence score indicating a probability of being a bat flight path. Using theses confidence scores from the BTT, we aimed at determining a threshold in this confidence score minimising false negative rate (Fig. 2 step 5).

For that, at first, we checked manually $1 \%$ of the dataset (i.e., an average of 5,000 flight paths) stratified on the survey point, the class of confidence score (10 classes distributed equitably) and the month. The observer then visually classified detected paths to be a bat or not. Finally, this observer binary variable was used in a general linear model (GLM), with a binomial distribution, to model the reliability of bat identification according to the confidence score from the BTT (explanatory variable). We retained a threshold of a minimum 5\% error risk as an optimum to minimise false positives and false negatives (Fig. 3).

\section{Determination of Relative Flight Heights above the Road}

For each bat flight path, we selected the lowest height value recorded within the flight path. Since a single camera was used for the evaluation of the bat flight height, it was necessary to estimate the depth of field. This was possible thanks to the landscape context which allowed the estimation of the bat crossing plan (a unique hedgerow bisected by the A 83 highway) (Fig. 1B and 1D).

Then, since the plan is distorted by perspective, we used projective geometry to assess bat flight height (Coxeter, 2003) (Fig. 4A, Fig. 2 step 6). Projective geometry requires four homologous reference points between the picture and the reality (Fig. 4A, points A to D). For videos before the installation of the bat overpass, we used the back of a semitrailer at the location of the future bat overpass as a reference point [Fig. 4B: points $A$ and $B$ : top of the semitrailer (height: $4 \mathrm{~m}$ ), points $C$ and $D$ : the bottom of semitrailer (height: $1.2 \mathrm{~m}$ )] (Council of the European Union, 1985: Council Directive 85/3/EEC of 19 December 1984 on the Weights, Dimensions and Certain Other Technical Characteristics of Certain Road Vehicles). For videos after the installation of the bat overpass, we used the bottom of the bat overpass (height: $6.08 \mathrm{~m}$; Fig. $4 \mathrm{C}$, points $\mathrm{C}$ and $\mathrm{D}$ ) and top of the bat overpass (height: $7.66 \mathrm{~m}$; Fig. 4C, points A and B) (VINCIautoroutes, 2017) as a reference point. 


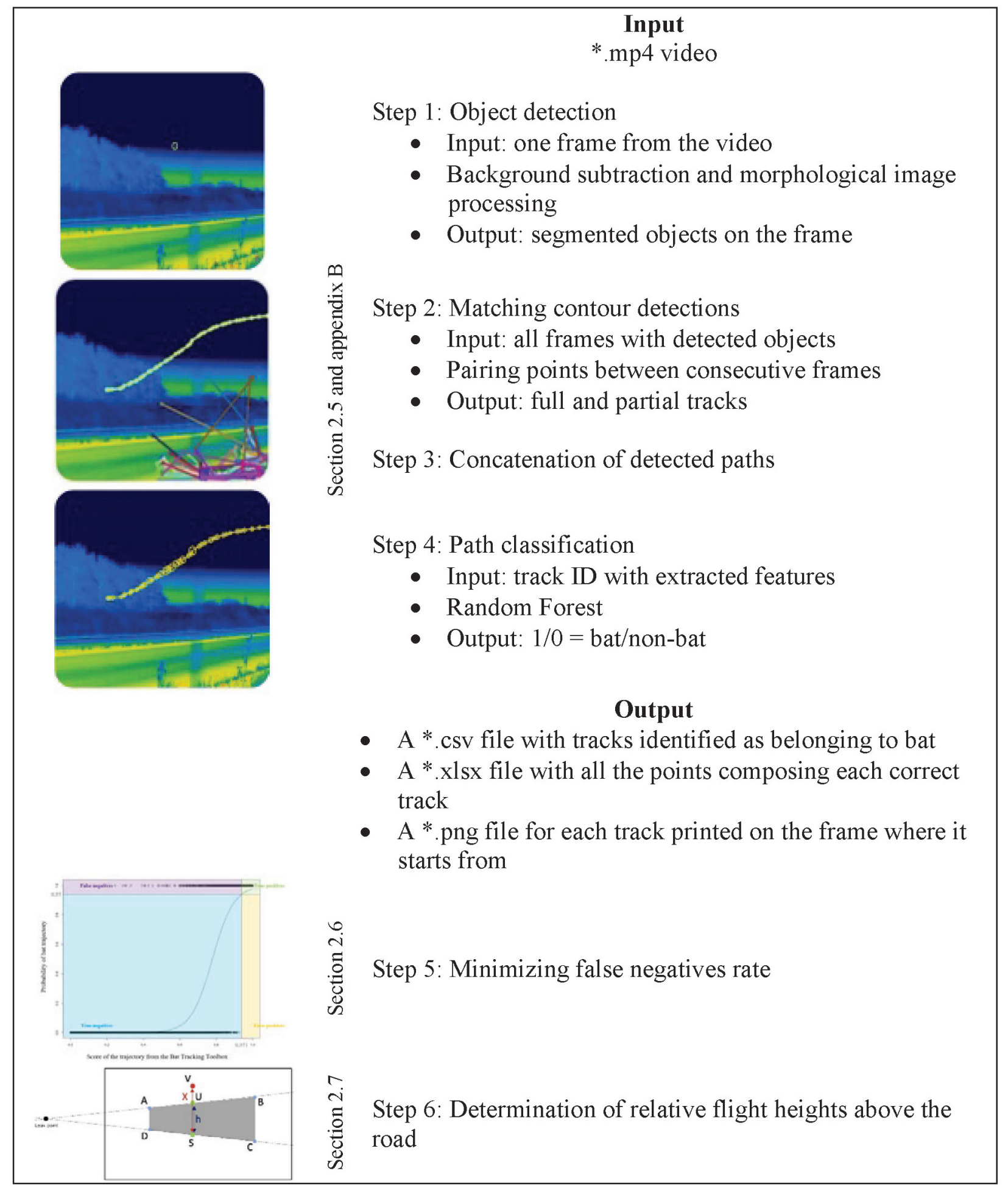

FIG. 2. Overview of the Bat Tracking Toolbox (BTT) processes step by step

Assessment of the Effect of the Bat Overpass Installation on Bat Flight Height

The BTT workflow applied on the video recording allowed us to estimate the height of bat flight paths crossing the road before and after the installation of the bat overpass. Using a linear mixed model (LMM, 'lme' function R package 'nlme' -
Pinheiro et al., 2019) we tested if these bat heights (our response variable) were influenced by the 'Period' (i.e., before or after installation of the bat overpass). To account for the possibility that bat flight behaviour could vary within the night (Rydell et al., 1996), we included 'Time' (number of minutes after sunset) as a second fixed effect in our model. In order to take into account the conditions of nights (e.g., effects of weather, temporal 


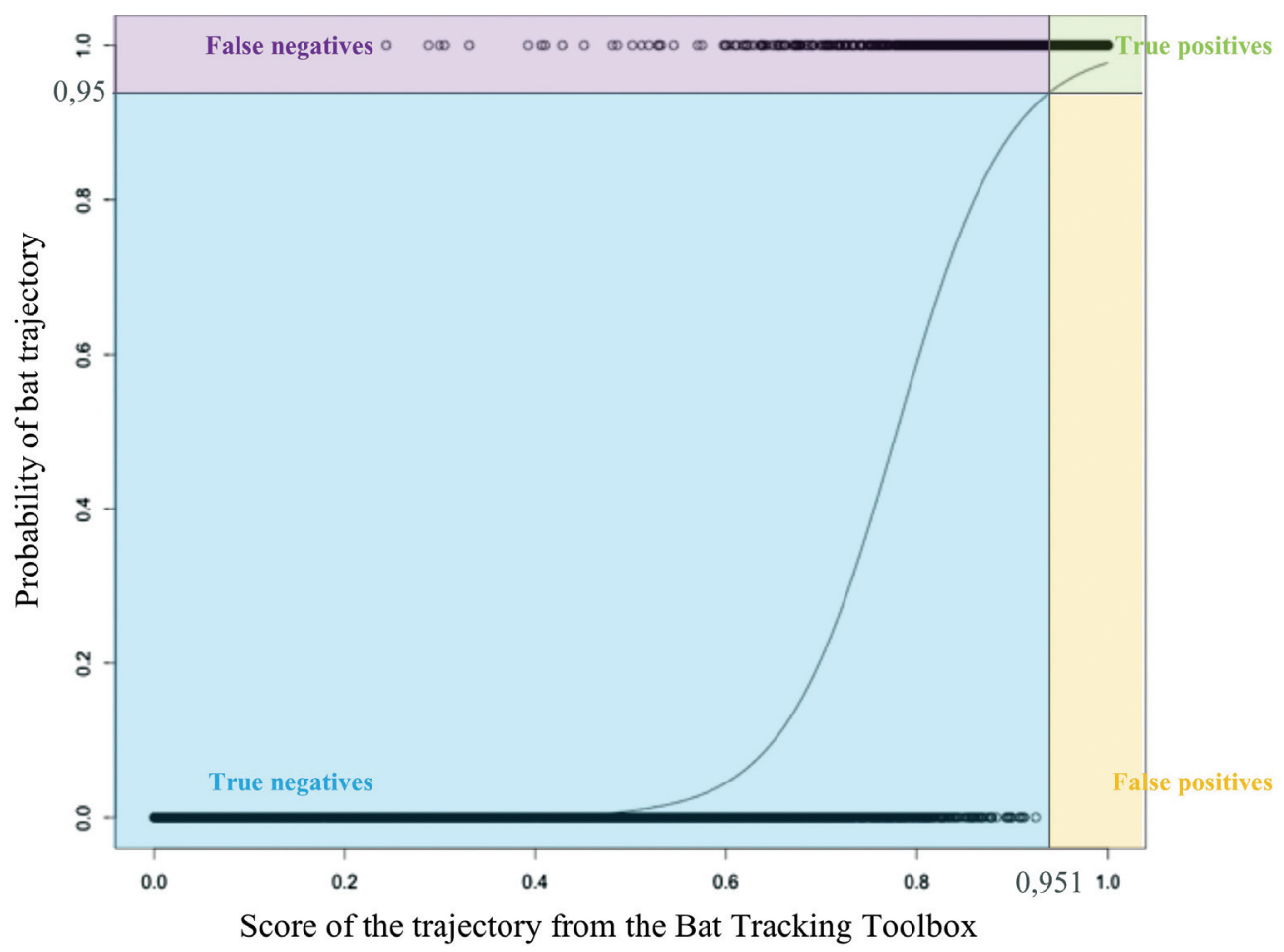

FIG. 3. Model fitted (GLM) using different scores from BTT of successes of being a bat allocated during manual verification of detected paths from the BTT (0, no-bat; 1 , bat)

correlation, seasonal effects) we tested three random effects: 'Point' (A and B) and 'Date' (year/month) separately and together using the maximum restricted likelihood (REML) of the $\mathrm{R}$ function lme and selected the most appropriate random effect comparing AIC values. The random effect selected was only 'Date'. Thus, the full model was written as follows:

\section{'Bat height' 'Period' + 'Time' + 1|'Date'}

Following the approaches of Chatterjee and Bose (2000) and Zuur et al. (2010), as all variables showed a VIF value $<3$ and the mean VIF values were $<2$, there was no evidence of multicollinearity. Following a multi model inference approach (Burnham et al., 2011) we generated a set of candidate models containing all possible variable combinations and ranked them by corrected Akaike information criterion (AIC). Furthermore, we evaluated the quality of our models by comparing them to the null model (including only the random effects) using Akaike's information criterion (AIC) (Mac Nally et al., 2017).

\section{RESULTS}

Running the Bat Tracking Toolbox workflow, we detected 268 bat flight paths: 42 before and 226 after the installation of the bat overpass (Figs. 5 and 6). The average height of flying bats was $6.1 \mathrm{~m}$ above the road before the installation of the bat overpass and $9.3 \mathrm{~m}$ after (Fig. 6).

The model selected demonstrate that the installation of the bat overpass increased significantly the height of flying bats $(P<0.01$ - Tables 2 and 3$)$. Moreover, the proportion of bats crossing the road at collision risk (i.e., $<5 \mathrm{~m}-$ Berthinussen and Altringham, 2012a) was $19.05 \%$ before and $0.89 \%$ after the installation of the bat overpass (Fig. 6).

TABLE 2. Estimates, standard errors and $P$-values of the flight height before and after the bat overpass establishment of the selected model. The before period are the intercept in this model's summary

\begin{tabular}{lccc}
\hline & \multicolumn{2}{c}{ LMM'Bat height' $\sim$ 'Period' + 'Time' + 1|'Date' } \\
\cline { 2 - 3 } & \multicolumn{1}{c}{ Variables } & SE & $P$-value \\
\hline (Intercept) & 9.133 & 0.487 & $<0.001$ \\
Period before & -2.955 & 0.782 & $<0.01$ \\
Time & $/$ & $/$ & $/$ \\
AIC selected model & 1081.62 & \\
AIC null model & 1089.72 & \\
\hline
\end{tabular}

Legend: '/ - not selected in the best model 


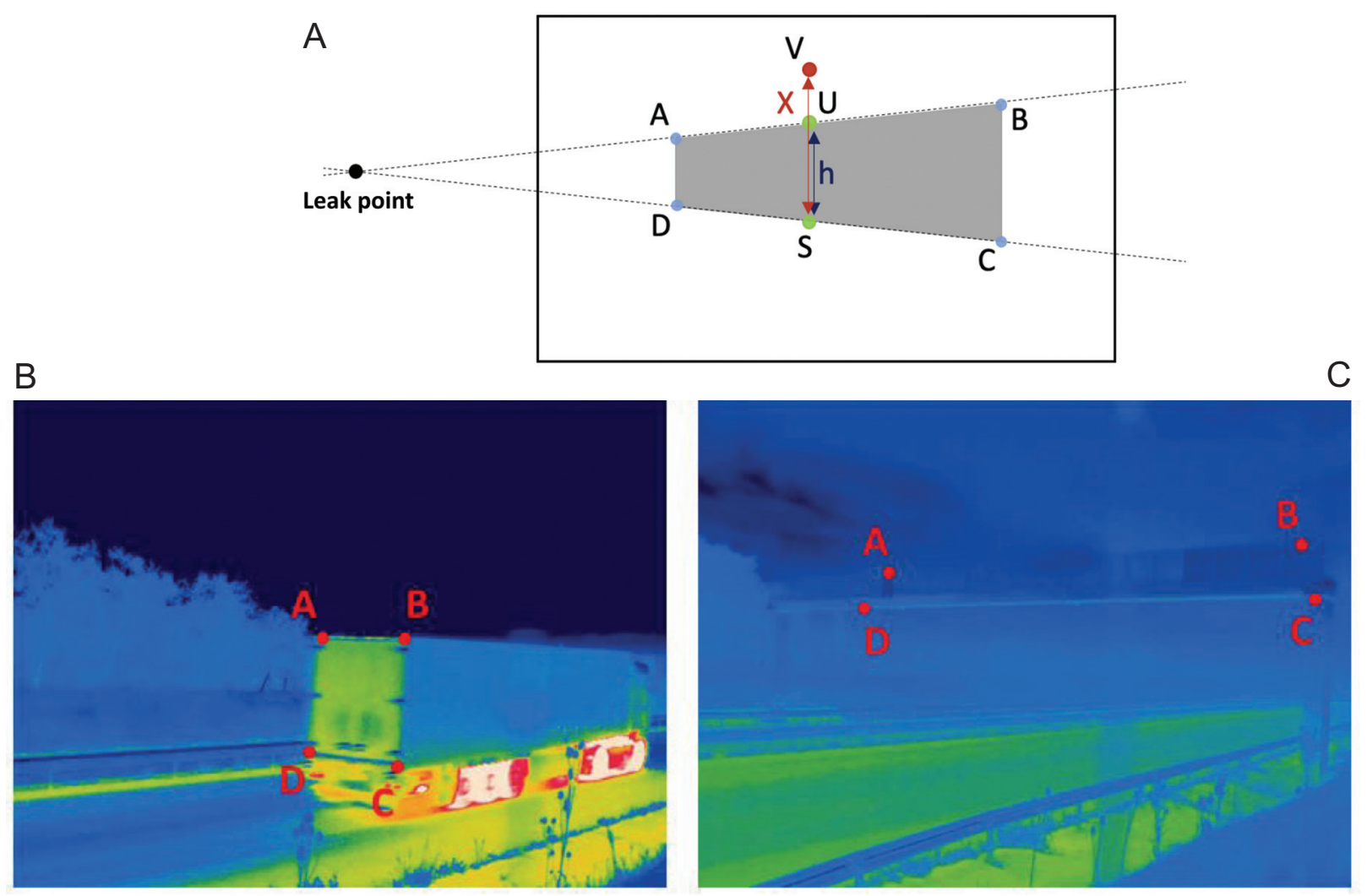

FIG. 4. A - Illustration of the method used for the evaluation of bat flight height (Coxeter, 2003). Black border, thermal image from camera; V, target (bats); Grey area, back of a semi-trailer or bat overpass; A, B, C, D, reference points; points U \& S, value respectively projected on the reference lines $\mathrm{AB}$ ) and $\mathrm{DC}$; h, distance between $\mathrm{AB}$ and $\mathrm{DC}$; X, bat flight height from DC. B Reference points before the installation of bat overpass. Height of A and B: top semi-trailer $(4 \mathrm{~m})$. Height of C and D: bottom of semi-trailer $(1.2 \mathrm{~m})$. C - Reference points with bat overpass. Height of A and B: bottom of bat overpass $(6.08 \mathrm{~m})$. Height of C and

D: top of bat overpass $(7.66 \mathrm{~m})$

\section{DisCUSSION}

We demonstrated that bat flight height increased significantly after the installation of the bat overpass, thus reducing drastically the proportion of bats crossing the road at collision risk. In addition, even if this approach has not a control-impact design (BACI), our study using thermal video recordings highlights an increase of the number of bat crossings after the installation of the bat
A

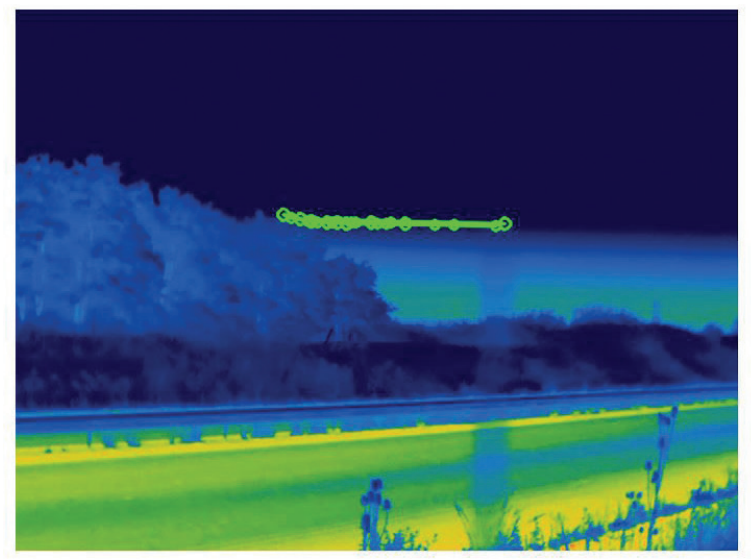

B

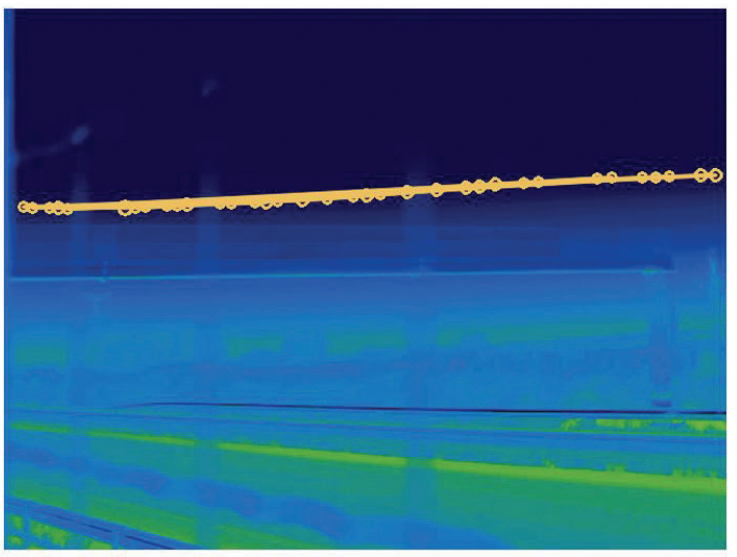

FIG. 5. A - Bat flight path before the installation of the bat overpass. B - Bat flight path after the installation of the bat overpass 


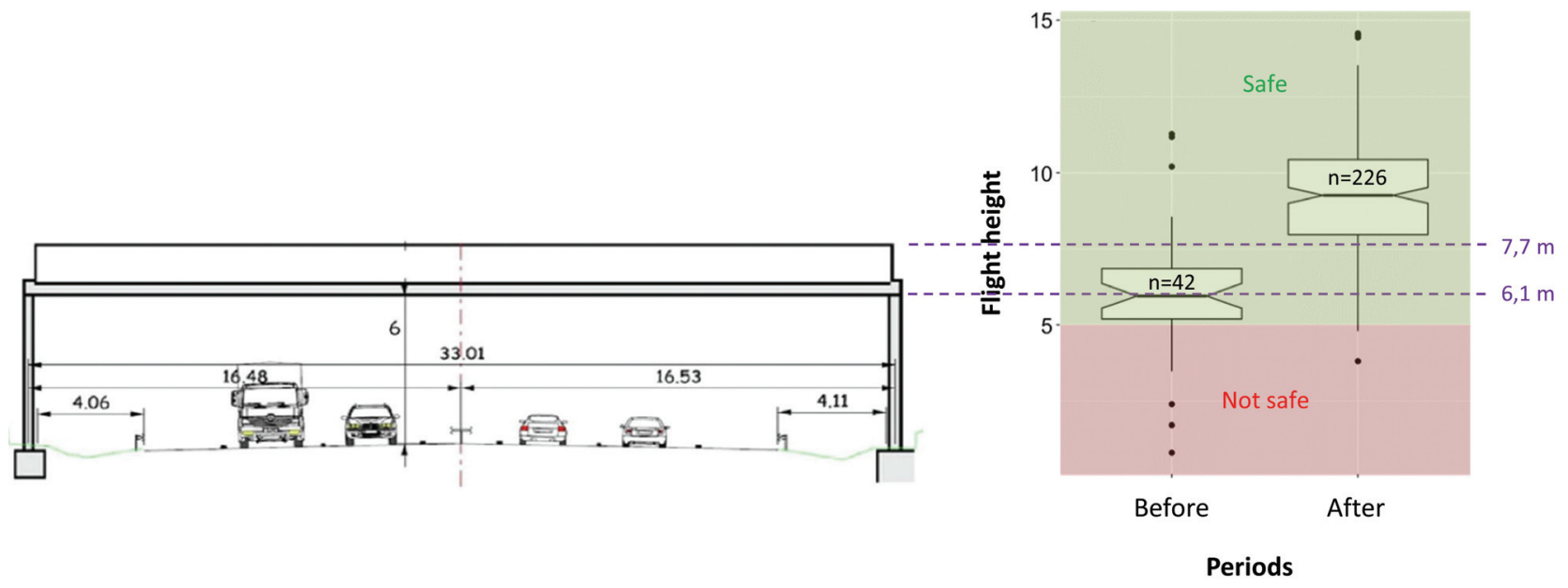

FIG. 6. Bat flight height before and after the installation of the bat overpass

overpass. This result is congruent with a previous study based on a BACI design and involving an acoustic method (Claireau et al., 2019b).

In the present experiment, the bat overpass reduced the number of bats crossings at collision risk from $20 \%$ to $1 \%$. Nevertheless, as suggested by Sołowczuk (2019), the effectiveness of bat overpasses depend on general factors and main determinants. Indeed, our study site was located in an agricultural landscape dominated by intensive farming, with shoulders above the road (an average of $1.7 \mathrm{~m}$ ) and fences of $2 \mathrm{~m}$. In this context, bats commuting along hedgerows - themselves on embankments are prone to fly high above the road and probably less at collision risk (here, $80 \%$ of bat flight paths were in the safe zone before the installation of the bat overpass).

It would be important to replicate this experiment in another landscape context (less intensive agriculture, with more trees), with other configurations (road under shoulder or at the same height) and in the same seasons to confirm our findings. Also, the results might depend on the species community as all species do not behave the same way when crossing roads. In our case, the community is dominated by Pipistrellus spp. (87\%) (Claireau et al., $2019 b$ ), meaning that our conclusions mostly apply to these aerial species.
Finally, the development of the bat tracking toolbox (BTT) is a useful approach to measure bat behavioural responses in before-after studies. This innovative method significantly reduces observer bias [i.e., uncertainties on the estimation (Erwin, 1982; Cunningham et al., 1999; Diefenbach et al., 2003; Frederick et al., 2003), the experience (Fitzpatrick et al., 2009), learning effect (Kendall et al., 1996; Jiguet, 2009) and their perception or representation (Tuyttens et al., 2014)]. Moreover, the BTT saves considerable time in analysing thermal videos and represents a good compromise between costs and benefits.

\section{Conclusions}

Our study is one of the first evidences that bat overpasses can increase bat flight height above the road. Added to findings from Claireau et al. (2019a), who found an increase in habitat connectivity, bat overpasses are thus possibly an (partially) effective mitigation measure in road ecology. Nevertheless, we recommend to replicate this before-after study design in other study sites to confirm our findings. Finally, roads remain a loss of biodiversity and mitigation measures cannot operate alone; offset measures have to be implemented in order to have a no-net-loss of biodiversity.

TABLE 3. Full, selected and null models with their AIC

\begin{tabular}{llcc}
\hline \multicolumn{1}{c}{ Models } & \multicolumn{1}{c}{ Variables } & AIC & $\Delta$ AIC selected model to null model \\
\hline Full model & 'Bat height' $\sim$ 'Period' + 'Time' + 1|'Date' & 1092.42 & \\
Selected model & 'Bat height' $\sim$ 'Period' + 1|'Date' & 1081.62 & 8.1 \\
Null model & $1+1 \mid$ 'Date' & 1089.72 & \\
\hline
\end{tabular}




\section{SUPPLEMENTARY INFORMATION}

Contents: Supplementary Appendices: Appendix S1. Known bat activity in the study area; Appendix S2. Bat Tracking Toolbox processes. Supplementary Information is available exclusively on BioOne.

\section{ACKNOWLEDGEMENTS}

We would like to sincerely thank our technical partners, especially Cédric Heurtebise, Claire Mestre and Philippe Chavaren from "VINCI-autoroutes". Thanks go Mircea Sofonea for suggesting the use of projective geometry, to Koox-production for drone photography of the study site and to Charlotte Roemer for the proofreading of this manuscript. This research was supported by 'Naturalia Environnement' and 'Association Nationale de la Recherche et de la Technologie' (grant number: 2015/0893).

Conflict of interest. Naturalia Environnement is an environmental firm involved in road impact assessment studies. Three of the authors, Fabien Claireau, Thibaut Ferraille and Benjamin Allegrini, worked at Naturalia Environnement at the time of submission. Fabien Claireau did his Ph.D. between 2015 and 2018 at the French National Museum of Natural History co supervised with the University of Greifswald in Germany and founded by Naturalia Environnement. Two of the authors, Flavien Charton and Cédric De Almeida Braga, did their engineer internship at Naturalia Environnement respectively in 2017 and 2018. Authors thus declare a direct conflict of interest according to BioOne ethics. All data used and analysed in this study were carried out only under the supervision of the two laboratories. All authors furthermore take complete responsibility for the integrity of the data related to flight behaviour and the accuracy of.

\section{LiTERATURE Cited}

Abbott, I. M., A. Berthinussen, E. Stone, M. Boonman, M. Melber, and J. Altringham. 2015. Bats and roads. Pp. 290-299, in Handbook of road ecology (R. VAN DER REE, D. J. Smith, and C. GRILO, eds.). John Wiley \& Sons, Ltd, Chichester, UK, 552 pp.

BenNeTt, V. J. 2017. Effects of road density and pattern on the conservation of species and biodiversity. Current Landscape Ecology Reports, 2: 1-11.

Berthinussen, A., and J. Altringham. 2012a. Do bat gantries and underpasses help bats cross roads safely? PLoS ONE, 7: e38775.

Berthinussen, A., and J. Altringham. 2012b. The effect of a major road on bat activity and diversity: effect of a major road on bat activity. Journal of Applied Ecology, 49: 82-89.

Burnham, K. P., D. R. Anderson, and K. P. Huyvaert. 2011. AIC model selection and multimodel inference in behavioral ecology: some background, observations, and comparisons. Behavioral Ecology and Sociobiology, 65: 23-35.

Chatterjee, S., and A. Bose. 2000. Variance estimation in high dimensional regression models. Statistica Sinica, 10: 497-515.

Claireau, F., Y. Bas, S. J. Puechmaille, J. Julien, B. AlleGRINI, and C. KERBIRIOU. 2019a. Bat overpasses: an insufficient solution to restore habitat connectivity across roads. Journal of Applied Ecology, 56: 573-584.
Claireau, F., Y. Bas, J.-F. Julien, N. Machon, B. Allegrini, S. J. Puechmaille, and C. Kerbiriou. 2019b. Bat overpasses as an alternative solution to restore habitat connectivity in the context of road requalification. Ecological Engineering, 131: 34-38.

Clatreau, F., Y. Bas, J. Pauwels, K. Barré, N. Machon, B. Allegrini, S. J. Puechmaille, and C. Kerbiriou. 2019 c. Major roads have important negative effects on insectivorous bat activity. Biological Conservation, 235: 53-62.

CoXeter, H. S. M. 2003. Projective geometry, 2nd edition, 1., softcover print. Springer, New York, $162 \mathrm{pp}$.

Cunningham, R. B., D. B. Lindenmayer, H. A. Nix, and B. D. LINDENMAYER. 1999. Quantifying observer heterogeneity in bird counts. Austral Ecology, 24: 270-277.

Cutler, D. R., T. C. Edwards, K. H. Beard, A. Cutler, K. T. Hess, J. Gibson, and J. J. LAwLER. 2007. Random forests for classification in ecology. Ecology, 88: 2783-2792.

Diefenbach, D. R., D. W. Brauning, and J. A. Mattice. 2003. Variability in grassland bird counts related to observer differences and species detection rates. The Auk, 120: 1168.

ERWIN, R. M. 1982. Observer variability in estimating numbers: an experiment. Journal of Field Ornithology, 53: 159-167.

Fensome, A. G., and F. MAthews. 2016. Roads and bats: a metaanalysis and review of the evidence on vehicle collisions and barrier effects. Mammal Review, 46: 311-323.

Fitzpatrick, M. C., E. L. Preisser, A. M. Ellison, and J. S. ELKINTON. 2009. Observer bias and the detection of low-density populations. Ecological Applications, 19: 1673-1679.

Forman, R. T. T. 2000. Estimate of the area affected ecologically by the road system in the United States. Conservation Biology, 14: 31-35.

Forman, R. T. T., and R. D. Deblinger. 2000. The ecological road-effect zone of a Massachusetts (U.S.A.) Suburban Highway. Conservation Biology, 14: 36-46.

Forman, R. T. T., and L. E. AleXANDER. 1998. Roads and their major ecological effects. Annual Review of Ecology and Systematics, 29: 207-231.

Frederick, P. C., B. Hylton, J. A. Heath, and M. Ruane. 2003. Accuracy and variation in estimates of large numbers of birds by individual observers using an aerial survey simulator. Journal of Field Ornithology, 74: 281-287.

Frey-Ehrenbold, A., F. Bontadina, R. Arlettaz, and M. K. OBRIST. 2013. Landscape connectivity, habitat structure and activity of bat guilds in farmland-dominated matrices. Journal of Applied Ecology, 50: 252-261.

Hale, J. D., A. J. Fairbrass, T. J. Matthews, and J. P. Sadler. 2012. Habitat composition and connectivity predicts bat presence and activity at foraging sites in a large UK conurbation. PLoS ONE, 7: e33300.

Jiguet, F. 2009. Method learning caused a first-time observer effect in a newly started breeding bird survey. Bird Study, 56: 253-258.

Kendall, W. L., B. G. Peterjohn, and J. R. Sauer. 1996. Firsttime observer effects in the North American Breeding Bird Survey. The Auk, 113: 823-829.

KitZes, J., and A. MerenLEnDER. 2014. Large roads reduce bat activity across multiple species. PLoS ONE, 9: e96341.

Krauss, J., R. Bommarco, M. Guardiola, R. K. Heikkinen, A. Helm, M. Kuussaari, R. Lindborg, E. Öckinger, M. PÄRTEL, J. PINO, et al. 2010. Habitat fragmentation causes immediate and time-delayed biodiversity loss at different trophic levels: Immediate and time-delayed biodiversity loss. Ecology Letters, 13: 597-605. 
Laforge, A., F. Archaux, Y. Bas, N. Gouix, F. Calatayud, T. LATGE, and L. BARBARO. 2019. Landscape context matters for attractiveness and effective use of road underpasses by bats. Biological Conservation, 237: 409-422.

Mac Nally, R., R. P. Duncan, J. R. Thomson, and J. D. L. YEN. 2017. Model selection using information criteria, but is the 'best' model any good? Journal of Applied Ecology, 2017: 1-4.

Maxwell, S. L., R. A. Fuller, T. M. Brooks, and J. E. M. WATSON. 2016. Biodiversity The ravages of guns, nets and bulldozers. Nature, 536: 143-145.

Medinas, D., J. T. Marques, and A. Mira. 2013. Assessing road effects on bats: the role of landscape, road features, and bat activity on road-kills. Ecological Research, 28: 227-237.

Medinas, D., V. Ribeiro, J. T. Marques, B. Silva, A. M. BarBosa, H. ReBelo, and A. Mira. 2019. Road effects on bat activity depend on surrounding habitat type. Science of the Total Environment, 660: 340-347.

Medinas, D., J. T. Marques, P. Costa, S. Santos, H. Rebelo, A. M. BARBosA, and A. MirA. 2021. Spatiotemporal persistence of bat roadkill hotspots in response to dynamics of habitat suitability and activity patterns. Journal of Environmental Management, 277: 111412.

MEEM [Ministère DE L'ENVIRONNEMENT, DE L'ÉNERGIE ET DE LA MER]. 2017. Chiffres Clés Du Transport —Édition 2017. Ministère de l'Environnement, de l'Énergie et de la Mer, en charge des relations internationales sur le climat.

Møller, J. D., J. Dekker, H. J. BaAgøe, I. Garin, A. Alberdi, M. Christensen, and M. Elmeros. 2016. Effectiveness of mitigating measures for bats - a review. CEDR Transnational Road Research Programme. CEDR Call 2013: Roads and Wildlife, 1-72 pp.

Naturalia EnVironnement. 2019. Expérimentation de La Pose d'un Portique En Vue de Favoriser Le Franchissement Des Chauves-Souris En Toute Sécurité (85).

Newson, S. E., H. E. Evans, and S. Gillings. 2015. A novel citizen science approach for large-scale standardised monitoring of bat activity and distribution, evaluated in eastern England. Biological Conservation, 191: 38-49.
Pinaud, D., F. Claireau, M. Leuchtmann, and C. Kerbiriou. 2018. Modelling landscape connectivity for greater horseshoe bat using an empirical quantification of resistance. Journal of Applied Ecology, 55: 2600-2611.

Pinheiro, J., D. Bates, S. DebRoy, D. Sarkar, and R Core TEAM. 2019. Nlme: linear and nonlinear mixed effects models. R package version 3.1-151. Available at https://CRAN. R-project.org/package $=$ nlme.

QuinN, J. F., and S. P. HARRISON. 1988. Effects of habitat fragmentation and isolation on species richness: evidence from biogeographic patterns. Oecologia, 75: 132-140.

Roemer, C., A. Coulon, T. Disca, and Y. Bas. 2019. Bat sonar and wing morphology predict species vertical niche. Journal of the Acoustical Society of America, 145: 3242-3251.

Rydell, J., A. Entwistle, and P. A. RAcey. 1996. Timing of foraging flights of three species of bats in relation to insect activity and predation risk. Oikos, 76: 243.

Saunders, D. A., R. J. Hobbs, and C. R. Margules. 1991. Biological consequences of ecosystem fragmentation: a review. Conservation Biology, 5: 18-32.

SoŁowcZuK, A. 2019. Determinants of the performance of bat gantries installed to carry bat commuting routes over the S3 expressway in Poland. Symmetry, 11: 1022.

Trombulak, S. C., and C. A. Frissell. 2000. Review of ecological effects of roads on terrestrial and aquatic communities. Conservation Biology. 14: 18-30.

Tuyttens, F. A. M., S. De GraAf, J. L. T. Heerkens, L. Jacobs, E. Nalon, S. Ott, L. Stadig, E. Van Laer, and B. Ampe. 2014. Observer bias in animal behaviour research: can we believe what we score, if we score what we believe? Animal Behaviour, 90: 273-280.

VAN DER ReE, R., D. J. SMITh, and C. GRILo (eds.). 2015. Handbook of road ecology. John Wiley \& Sons, Ltd, Chichester, UK, $552 \mathrm{pp}$.

VINCI-Autoroutes. 2017. Chiropétroduc A83: hauteurs relevées sous la poutre pour chaque sens, $2 \mathrm{pp}$.

ZuUR, A. F., E. N. IENO, and C. S. ELPHICK. 2010. A protocol for data exploration to avoid common statistical problems: data exploration. Methods in Ecology and Evolution, 1: 3-14. 